УДК 336.58

$10.17213 / 2075-2067-2021-3-149-153$

\title{
ПЕРСПЕКТИВЫ РАЗВИТИЯ ЦИФРОВИЗАЦИИ БАНКОВСКИХ ГАРАНТИЙ В СЕГМЕНТЕ ГОСУДАРСТВЕННЫХ И МУНИЦИПАЛЬНЫХ ЗАКУПОК
}

\author{
(C) 2021 г. Л. В. Голощцапова, О. И. Чуприна
}

\section{Российский экономический университет имени Г. В. Плеханова, г. Москва, Россия}

Цель исследования. В исследовании рассматриваются актуальные перспективы цифрровизации банковских гарантий в сегменте государственных закупок. Представлень аргументы, обосновывающие необходимость активного внедрения циифровых банковских гарантий. С каждым годом механизм функиионирования государственных закупок становится более технологичным, упрощаются закупочные прочессы, применяются новейшие технологии, такие изменения заставляют переводить каждый этап сделки в электронный формат, в том числе и банковские гарантии, что становится особенно актуальным в условиях санкиионного ограничения и дистантной работы.

Цель исследования - провести анализ и оценку внедрения иүифровых банковских гарантий на рынке государственных и муниципальных закупок.

Материалы, методы и условия проведения исследований. Изучены нормативноправовые акты, а именно - федеральный закон от 05.04.2013 №44-Ф3 «О контрактной системе в сфере закупок товаров, работ, услуг для обеспечения государственных и муниципальных нужд» и федеральный закон от 18.07.2011 №223-Ф3 «О закупках товаров, работ, услуг отдельными видами юридических лиц».

Задачи исследования - проанализировать и оценить ичелесообразность внедрения цифровых банковских гарантий в сферу государственных и муниципальных закупок в современных условиях.

Перспектива исследования. Банковские гарантии все чаще используются поставщиками в качестве обеспечения контрактов, а в эпоху циифровых технологий, когда каждый этап закупочного прочесса переходит в электронный формат. Немаловажную роль играет переход банковских гарантий в полностью ичифровой вид, однако в настоящее время нет технических возможностей осуществить этот переход полностью.

Ключевые слова: государственные и муниципальные закупки; обеспечение контрактов; банковские гарантии; циифровизащия; блокчейн.

\section{PROSPECTS FOR THE DEVELOPMENT \\ OF DIGITALIZATION OF BANK GUARANTEES IN THE SEGMENT OF STATE AND MUNICIPAL PROCUREMENT}

\section{(C) 2021 L. V. Goloshchapova, O. I. Chuprina}

\section{Plekhanov Russian University of Economics, Moscow, Russia}

The aim of the study. The study examines the current prospects for digitalization of bank guarantees in the public procurement segment. The arguments justifying the need for active implementation of digital bank guarantees are presented. Every year, the mechanism of functioning 
of public procurement becomes more technologically advanced, procurement processes are simplified, the latest technologies are used, such changes make it necessary to transfer each stage of the transaction to an electronic format, including bank guarantees, which becomes especially relevant in the context of sanctions restrictions and remote work.

The purpose of the study - to analyze and evaluate the implementation of digital bank guarantees in the market of state and municipal procurement.

Materials, methods and conditions for conducting research. We studied the normative legal acts, namely Federal Law №44-FZ of 05.04.2013 «On the Contract System in the field of Procurement of Goods, Works, and Services for State and Municipal Needs» and Federal Law №223-FZ of 18.07.2011 «On Procurement of Goods, Works, and Services by Certain Types of Legal Entities».

Research objectives - to analyze and evaluate the feasibility of introducing digital bank guarantees in the field of state and municipal procurement in modern conditions.

Research perspective. Bank guarantees are increasingly used by suppliers as security for contracts, and in the digital age, when every stage of the procurement process is moving to an electronic format. The transition of bank guarantees to a fully digital form plays an important role. However, there is currently no technical capacity to fully implement this transition.

Key words: state and municipal procurement; contract security; bank guarantees; digitalization; blockchain.

В настоящее время использование цифровых технологий в сферах экономики, политики, образования, промышленности и в целом в повседневной жизни является неотъемлемой частью нашей реальности. Внедрение их позволяет упростить и автоматизировать рабочие процессы, снизить риск влияния человеческого фактора на результат.

Под цифровой экономикой (веб-экономикой, интернет-экономикой, digital economy) в самом упрощенном изложении понимается система экономических и правовых отношений, основанных на использовании цифровых технологий [3].

Рынок государственных и муниципальных закупок - не исключение. Внедрение цифровых технологий приводит к упрощению механизма работы единой информационной системы (ЕИС), применению электронного документооборота на каждом этапе заключения сделок, а также прозрачности закупок и повышению конкуренции среди потенциальных подрядчиков. Однако для полной цифровизации такого процесса необходимо введение и электронных банковских гарантий.

Банковская гарантия - это обязательство, выданное банком-гарантом по просьбе принципала, уплатить денежные средства бенефициару по письменному требованию, если принципал не выполнит полностью или частично обязательства по контракту.

Анализ реестра банковских гарантий показал, что за 9 месяцев в 2020 году банки выпустили 529816 банковских гарантий на сумму более чем 1 трлн. рублей. Однако по сравнению с 2019 годом количество банковских гарантий уменьшилось на $8,4 \%$, а их объем увеличился на $11 \%$.

Статья 45 Ф3-44 регламентирует пункты, которые должна содержать безотзывная банковая гарантия: сумму, срок БГ, обязательства принципала, которые обеспечиваются БГ, отлагательное условие и т.д. Отсутствие хотя бы одного из этих пунктов может повлечь за собой отказ заказчика от заключения контракта с принципалом и признание поставщика уклонистом.

Банковские гарантии имеют ряд преимуществ:

- позволяют принципалу не выводить из оборота компании собственные денежные средства, которые могут быть направлены на другие цели;

- дают возможность поставщику участвовать не в одной закупке, а в нескольких, что 
Динамика банковских гарантий за 2019-2020 гг.

\begin{tabular}{|c|c|c|c|}
\hline \multicolumn{2}{|l|}{ Параметр/период } & 2019 год & 2020 года \\
\hline \multirow{3}{*}{$\begin{array}{l}\text { Количество выданных банковских гарантий, } \\
\text { шт. }\end{array}$} & I квартал & 145307 & 157609 \\
\hline & II квартал & 219785 & 205990 \\
\hline & III квартал & 213534 & 166217 \\
\hline \multirow{3}{*}{$\begin{array}{l}\text { Объем выданных банковских гарантий, } \\
\text { млрд. руб. }\end{array}$} & I квартал & 160 & 304,3 \\
\hline & II квартал & 351,8 & 393,5 \\
\hline & III квартал & 396,9 & 324,7 \\
\hline
\end{tabular}

соответственно увеличивает шансы на заключение контракта;

- предоставление БГ на гарантийные обязательства позволяет принципалу получить полную сумму по контракту сразу после его выполнения, а не частично, так как по закону №44-Ф3 предусмотрено удержание определенной суммы бенефициаром от цены контракта на срок гарантийных обязательств.

По оценкам аналитиков, высоким спросом пользуются банковские гарантии на исполнение государственных контрактов. В то же время этот вид гарантий для банков самый рискованный: претензий к подрядчику по качеству работ и используемых материалов становится все больше. На втором месте с большим отрывом идут гарантии на участие в торгах, обязывающие победителя конкурса подписать договор с государственным заказчиком. Они, напротив, имеют самые низкие риски. Реже всего поставщики обращаются в банки за гарантиями для обеспечения гарантийных обязательств.

Для того чтобы получить банковскую гарантию, у поставщика есть два варианта: обратиться напрямую в банк или к финансовому агенту, у которого заключены договоры со множеством банков. Затем, предоставив определенный список запрашиваемых документов, объем которого зависит от финансового состояния компании, опыта участия в государственных закупках, наличия негативных факторов, например, исполнительных производств арбитражей, где поставщик выступает ответчиком, банк проводит анализ поставщика, после которого второй получает или не получает одобрение на выдачу банковской гарантии.
В некоторых банках уже происходит рассмотрение заявок на небольшие суммы банковских гарантий (примерно до 1-1,5 млн. рублей) автоматически с помощью цифровых технологий. Однако на более крупные суммы банковских гарантий необходимо более детальное рассмотрение компании принципала с применением знаний аналитиков. После оплаты комиссии происходит выпуск банковской гарантии, как правило, в бумажной форме и размещение ее сканов в реестре банковских гарантий. Получается, что с момента выпуска до полного прекращения срока действия банковской гарантии цифровые технологии применяются не в полном объеме.

Однако, если привести банковскую гарантию полностью в структурированный цифровой формат, то это позволит:

- упростить и ускорить процесс проверки подлинности выданной гарантии;

- уменьшить количество спорных ситуаций при принятии заказчиком банковской гарантии, а также в случаях предъявления требований по ней;

- унифицировать форму банковской гарантии для большинства заказчиков по федеральному закону №223-Ф3, в том числе для OAО «РЖД», Госкорпорации «Росатом»;

- сократить транзакционные издержки участников сделок;

— избавить от необходимости получения оригинала банковской гарантии, так как цифровой формат будет приравнен к оригиналу.

Опыт выдачи такого формата банковской гарантии был проведен впервые в декабре 2020 года банком «ВТБ» с помощью российской блокчейн-платформы Мастерчейн. 
Мастерчейн - первая сертифицированная в России блокчейн-платформа, в которой используются российские средства криптографической защиты информации. Платформа разработана Ассоциацией «ФинТех» совместно с Банком России и участниками финансового рынка [6]. Банком была выдана банковская гарантия на исполнение платежных обязательств на сумму 392 млн. рублей в пользу ПАО «МТС». Сделка прошла в режиме реального времени, цифровая гарантия, выпущенная банком «ВТБ», была подписана усиленной квалифицированной подписью, ПАО «МТС» принял ее, направив уведомление в банк. Применение данной технологии позволит повысить прозрачность сделок, конфиденциальность, так как вся информация сохраняется в зашифрованном виде, а для проведения какой-либо операции требуется определенный код доступа.

Однако для общего применения такой блокчейн-технологии всеми российскими банками необходимо обеспечить правовое регулирование этой технологии на законодательном уровне, решить вопрос ее финансирования, разработать регламент безопасности и технические требования.

\section{Литература}

1. Федеральный закон «О контрактной системе в сфере закупок товаров, работ, услуг для обеспечения государственных и муниципальных нужд» от 05.04.2013 г. №44-Ф3 (в ред. от 24.04.2020 г.) [Электронный ресурс]. - Режим доступа: http://www. consultant.ru/.

2. Федеральный закон «О закупках товаров, работ, услуг отдельными видами юридических лиц» от 18.07.2011 г. №223-Ф3 (последняя редакция) [Электронный ресурс]. Режим доступа: http://www.consultant.ru/.

3. Шмелев М.В. Цифровые технологии в государственных и муниципальных закупках: будущее или реальность [Электронный ресурс] // Журнал «Актуальные проблемы российского права». - 2019. - Режим доступа: https://cyberleninka.ru/.

4. Цифровая банковская гарантия близко [Электронный ресурс] // Российская ежедневная онлайн-газета новостей о цифровой трансформации, телекоммуникациях, вещания и ИТ ComNews.ru. - Режим доступа: https://www.comnews.ru/.

5. Официальный сайт Министерства финансов РФ [Электронный ресурс]. — Режим доступа: https://minfin.gov.ru.

6. Официальный сайт ПАО «ВТБ» [Электронный ресурс]. - Режим доступа: https:// www.vtb.ru/o-banke/press-centr/novosti-i-pressrelizy/2020/12/2020-12-16-vtb-i-mts-pervymiproveli-sdelku-po-vydache-bankovskoy-garantiicherez-rossiyskuyu-blokch/.

\section{References}

1. Federal'nyj zakon «O kontraktnoj sisteme v sfere zakupok tovarov, rabot, uslug dlja obespechenija gosudarstvennyh i municipal'nyh nuzhd» ot 05.04.2013 g. №44-FZ (v red. ot 24.04.2020 g.) [Federal Law №44-FZ of 05.04.2013 «On the Contract System in the field of Procurement of Goods, Works, and Services for State and Municipal Needs» (as amended from 24.04.2020)] [Jelektronnyj resurs]. URL: http://www.consultant.ru/.

2. Federal'nyj zakon «O zakupkah tovarov, rabot, uslug otdel'nymi vidami juridicheskih lic»» ot 18.07.2011 g. №223-FZ (poslednjaja redakcija) [Federal Law №223-FZ of 18.07.2011 «On Procurement of Goods, Works, and Services by Certain Types of Legal Entities» (latest version)] [Jelektronnyj resurs]. — URL: http://www.consultant.ru/.

3. Shmelev M. V. Cifrovye tehnologii v gosudarstvennyh imunicipal'nyh zakupkah: budushhee ili real'nost' [Digital technologies in state and municipal procurement: the future or reality] [Jelektronnyj resurs] // Zhurnal «Aktual'nye problemy rossijskogo prava» [Journal «Actual problems of Russian law»]. — 2019. — URL: https://cyberleninka.ru/.

4. Cifrovaja bankovskaja garantija blizko [Digital bank guarantee is close] [Jelektronnyj resurs] // Rossijskaja ezhednevnaja onlajn-gazeta novostej o cifrovoj transformacii, telekommunikacijah, veshhanija i IT ComNews.ru [Russian daily online news newspaper about digital transformation, telecommunications, broadcasting and IT ComNews.ru]. - URL: https://www. comnews.ru/.

5. Oficial'nyj sajt Ministerstva finansov RF [Official website of the Ministry of Finance of 
the Russian Federation] [Jelektronnyj resurs]. URL: https://minfin.gov.ru.

6. Oficial'nyj sajt PAO «VTB» [Official website of PJSC «VTB»] [Jelektronnyj resurs]. URL: https://www.vtb.ru/o-banke/press-centr/ novosti-i-press-relizy/2020/12/2020-12-16vtb-i-mts-pervymi-proveli-sdelku-po-vydachebankovskoy-garantii-cherez-rossiyskuyublokch/.

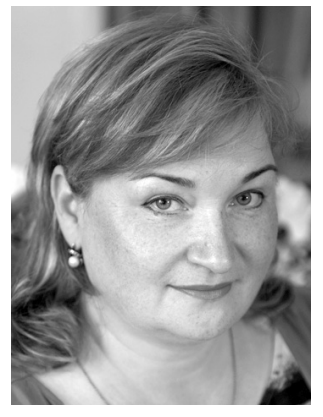

Голощапова Людмила Вячеславовна - кандидат экономических наук, доцент базовой кафедры финансового контроля, анализа и аудита Главного контрольного управления города Москвы Российского экономического университета имени Г.В. Плеханова.

Goloshchapova Liudmila Vyacheslavovna - Candidate of Economic Sciences, Associate Professor of the Basic Department of Financial control, Analysis and Audit of the Main Control Department of Moscow, Plekhanov Russian University of Economics.

117997, г. Москва, Стремянный пер., 36

36 Stremyanny ln., 117997, Moscow, Russia

E-mail: cool.lvg2012@yandex.ru

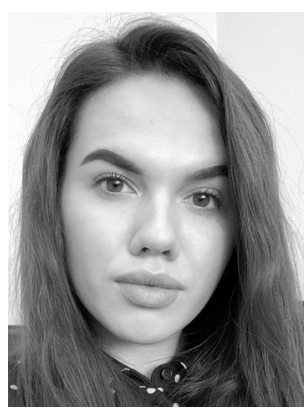

Чуприна Ольга Игоревна - студентка 1 курса магистратуры базовой кафедры финансового контроля, анализа и аудита Главного контрольного управления города Москвы Российского экономического университета имени Г. В. Плеханова.

Chuprina Olga Igorevna - 1st year magistracy student of the Basic Department of Financial control, Analysis and Audit of the Main Control Department of Moscow, Plekhanov Russian University of Economics.

117997, г. Москва, Стремянный пер., 36

36 Stremyanny ln., 117997, Moscow, Russia

E-mail: cool.lvg2012@yandex.ru 